\title{
Deep Benign Fibrous Histiocytoma
}

National Cancer Institute

\section{Source}

National Cancer Institute. Deep Benign Fibrous Histiocytoma. NCI Thesaurus. Code C6492.

A rare, well-circumscribed, pseudo-encapsulated benign fibrous histiocytoma that arises entirely within the subcutaneous tissue or deep soft tissue. It usually affects the extremities or the head and neck region. It recurs locally in a minority of cases. 